\title{
Satisfação no Trabalho: Um estudo na Agência da Caixa Econômica Federal de Cícero Dantas - BA
}

\author{
Anderson Ribeiro Paixão ${ }^{1}$; Milka Alves Correia Barbosa ${ }^{2}$
}

\begin{abstract}
Resumo: Este trabalho tem como objetivo analisar o nível de satisfação no trabalho dos empregados de uma agência da Caixa Econômica Federal no Estado da Bahia. O referencial teórico que deu suporte ao estudo discute os conceitos e teorias relacionados à satisfação no trabalho. Trata-se de um estudo de caso com análise qualitativa e quantitativa de dados. O instrumento utilizado para coleta de dados foi o questionário da Escala de satisfação no trabalho (EST) em sua versão completa de 25 itens e entrevistas semi-estruturadas. Os resultados apontam que os trabalhadores da agência pesquisada estão satisfeitos quanto a satisfação geral no trabalho. A entrevista revela que os participantes sentem elevada satisfação com os colegas de trabalho, por outro lado, os participantes revelaram críticas quanto às condições de trabalho e quantidade de funcionários insuficiente. Corroborando os resultados da entrevista, os dados apresentados pelo questionário EST revelaram que a dimensão que obteve o maior índice de satisfação foi a dimensão "satisfação com os colegas" e a dimensão que obteve o menor índice foi a dimensão "satisfação com a natureza do trabalho".
\end{abstract}

Palavras chave: satisfação no trabalho, Gestão de Pessoas, trabalho bancário.

\section{Satisfaction At Work: A Study In The Economic Agency Caixa In Cícero Federal Dantas - Ba}

\begin{abstract}
This work aims to analyze the level of job satisfaction of the employees of an agency of the Caixa Econômica Federal in the State of Bahia. The theoretical referential that supported the study discusses the concepts and theories related to job satisfaction. This is a case study with qualitative and quantitative data analysis. The instrument used for data collection was the questionnaire of satisfaction scale work (EST) in its complete version of 25 items and semi-structured interviews. The results show that workers searched agency are satisfied as the overall job satisfaction. The interview reveals that participants feel high satisfaction with coworkers, on the other hand, participants revealed criticism regarding working conditions and insufficient amount of employees. Corroborating the results of the interview, the data presented by the questionnaire EST revealed that the dimension that had the highest level of satisfaction was the size "satisfaction with colleagues" and the dimension that had the lowest rate was the size "satisfaction with the nature of work ".
\end{abstract}

Keywords: job satisfaction, people management, banking work.

\section{Introdução}

O ambiente de trabalho é altamente propício ao estresse. Cumprir ordens, atingir metas, vencer desafios, superar problemas, conviver com pessoas com pensamentos, opiniões e objetivos diferentes, são algumas das atividades laborais que podem gerar recorrentes conflitos, clima desarmônico e insatisfação no trabalho.

\footnotetext{
${ }^{1}$ Pós-graduando em Gestão Pública da Universidade Federal do Vale do São Francisco - UNIVASF. Graduado em Ciências Contábeis pela Universidade de Uberaba - UNIUBE. E-mail: anderson.umburanas@ hotmail.com;

${ }^{2}$ Doutorado em Administração pela UFPE/PROPAD. Instituição do trabalho: Univasf, secretária de Educação à distância, Curso de Especialização em Gestão Pública. E-mail: milka.barbosa@univasf.edu.br.
} 
Reconhece-se que o indivíduo passa grande parte de seu tempo no trabalho, como descreveu Karl Marx (1996, p. 378) "a jornada de trabalho compreende diariamente as 24 horas completas, depois de descontar as poucas horas de descanso, sem as quais a força de trabalho fica totalmente impossibilitada de realizar novamente sua tarefa". Com tanto tempo dedicado ao trabalho, o ideal seria exercer atividades gratificantes e com as quais o sujeito se identificasse, ou pelo menos em um ambiente em que os valores pessoais fossem respeitados. Afinal, a satisfação no trabalho é mutuamente benéfica para o trabalhador e para a empresa.

Para o primeiro, estar satisfeito com trabalho significa que suas necessidades e expectativas podem estar sendo atingidas e que estão em um bom local para trabalhar. Já para a empresa, os benefícios vão desde a redução dos índices de absenteísmo, atrasos e rotatividade até a melhora nos índices de satisfação dos clientes (ROBBINS, 2005; CHIAVENATO; MATOS, 2009).

No contexto do trabalho bancário, sabe-se que o trabalhador enfrenta sobrecarga de volume de trabalho, insuficiência de pessoal, pressão por resultados, ameaças de perda de função ou até demissão. Em virtude do modelo de gestão por metas, criou-se a cultura da competição, em que vencer é fonte de prazer e realização e perder é altamente sofrível (MAXIMO; ARAUJO; ZAMBRONI-DESOUZA, 2014).

Apesar das condições citadas, há algo prazeroso no trabalho bancário. Conforme pesquisa realizada com gerentes de banco por Maximo, Araujo e Zambroni-de-Souza (2014), a principal fonte de prazer no trabalho apontada pelos participantes foi o atendimento aos clientes, destacando-se a possibilidade de ajudar diariamente várias pessoas, de contribuir para o sucesso e crescimento das mesmas e de receber os sinceros agradecimentos.

Preocupada com a satisfação de seus empregados a Caixa Econômica Federal (CAIXA), uma empresa pública, parceira estratégica do Governo Federal na execução de várias políticas públicas, adota políticas e programas para o alcance dos melhores índices de satisfação. Dentre eles, destaca-se a pesquisa de clima organizacional realizada sistemática e periodicamente, sendo a gestão do clima responsabilidade de todos a fim de propiciar o bem-estar (CAIXA, 2014).

Considerando esses aspectos introdutórios, o objetivo deste trabalho é analisar o nível de satisfação no trabalho dos empregados de uma agência da Caixa Econômica Federal no Estado da Bahia.

Como também, a presente investigação buscou contribuir para o aprimoramento da Gestão de Pessoas na unidade, com dados que podem servir de subsídios para ações que melhorem os itens insatisfatórios e mantenham os itens satisfatórios no que se refere à satisfação no trabalho.

$\mathrm{O}$ presente artigo encontra-se estruturado em cinco tópicos, incluindo este introdutório. $\mathrm{O}$ segundo tópico compreende a revisão da literatura abordando os temas satisfação no trabalho e o 
trabalho bancário; o terceiro trata da metodologia utilizada, o quarto da apresentação e análise dos resultados e o quinto das considerações finais.

\section{Satisfação no Trabalho}

Segundo Robbins (2005, p. 61), pode-se definir satisfação com o trabalho como "atitude geral de uma pessoa em relação ao trabalho que ela realiza". Para o autor, uma pessoa muito satisfeita apresenta atitudes positivas, enquanto uma pessoa insatisfeita apresenta atitudes negativas.

Por outro lado, satisfação no trabalho para Weiss $(2002$, p.175) é o julgamento avaliativo que o trabalhador faz sobre seu trabalho. Nesse sentido, Robbins (2005) acrescenta que a avaliação que o trabalhador faz de sua satisfação com o trabalho é resultante de uma complexa soma de diferentes fatores, como natureza do trabalho, remuneração, relacionamentos, supervisão e oportunidades de promoção.

Nessa mesma linha, Siqueira (2008) defende que satisfação no trabalho representa a totalização das experiências prazerosas vivenciadas pelo trabalhador, sendo que a fonte, origem ou foco são cada uma das cinco dimensões de satisfação no trabalho (o salário, os colegas, a chefia, as promoções e o próprio trabalho). Assim, investigar a satisfação no trabalho é avaliar o quanto, por exemplo, a convivência com colegas e chefes, as promoções conquistadas, o salário recebido e a própria realização das tarefas propiciam ao empregado sentimentos gratificantes ou prazerosos.

Pode-se afirmar também que a satisfação no trabalho se forma durante um período de tempo, na medida em que o empregado obtém informações sobre o ambiente de trabalho. Entretanto, é importante destacar que ela é dinâmica, podendo se deteriorar em período muito mais curto que o necessário para se desenvolver (DAVIS; NEWSTROM, 1992).

De outra perspectiva mais ampla, a satisfação no trabalho é parte da satisfação geral com a vida. Assim, a satisfação ou não com fatores externos (como família, saúde) podem influenciar a satisfação no trabalho, e vice-versa (DAVIS; NEWSTROM, 1992).

Nesse sentido, para Xavier (1973) os fatores que proporcionam um clima de satisfação no trabalho são segurança (ao passar dos anos cresce a importância da sensação de estabilidade); salário (o dinheiro recebido pode deixar as pessoas satisfeitas ou insatisfeitas, contudo, este item contribui mais com a insatisfação que com a satisfação); a organização (reputação da empresa junto à opinião pública); oportunidade de progresso (a falta de oportunidade de crescimento é forte justificativa para o indivíduo não gostar do trabalho); supervisão; o trabalho em si mesmo; participação (as pessoas tendem a valorizar aquilo que criam); os aspectos sociais do trabalho; as condições de trabalho (temperatura, iluminação, jornada de trabalho, entre outros); os benefícios (XAVIER, 1973). 
A esses fatores Chiavenato (2015) acrescenta que o convívio social, as experiências compartilhadas com os colegas de trabalho e um ambiente com comunicação aberta (transparente, sem ruídos e barreiras) também são fontes de satisfação no trabalho. O autor ainda afirma que o tipo de atividade exercida é o aspecto que mais influencia na satisfação da pessoa.

Sintetizando, Robbins (2005) aponta quatro fatores que levam a altos índices de satisfação, quais sejam: trabalho mentalmente desafiante (possibilidade de aplicar suas habilidades e capacidades, variedade de tarefas e liberdade); recompensas justas (salário justo levando em consideração as atribuições do cargo, o custo de vida e a média salarial do mercado, como também políticas e praticas de promoção justas); condições de trabalho apoiadoras (ambiente físico confortável e seguro, instalações limpas e modernas, equipamentos adequados); colegas colaboradores (interação social amigável entre colegas, chefe compreensivo).

Para Aziri (2011) a satisfação no trabalho impacta na motivação dos trabalhadores influenciando na produtividade das organizações. Por outro lado, Robbins (2005) esclarece que, do ponto de vista individual, a satisfação do funcionário não garante aumento de produtividade deste; seria, na verdade, o bom desempenho que aumentaria a satisfação do trabalhador, uma vez que o melhor desempenho tende a gerar reconhecimento verbal, aumento na remuneração e maior probabilidade de promoção.

Nessa discussão, o trabalho de Davis e Newstrom (1992) já mostrava que a relação satisfaçãodesempenho é muito mais complexa que acreditar que satisfação leva a aumento no desempenho. Para os autores o funcionário com bom desempenho tende a receber maiores recompensas econômicas, sociais e psicológicas, se o funcionário as considerar justas aumenta-se a satisfação, porém se o funcionário as considerar injustas a insatisfação se manifesta. Posteriormente o nível de satisfação afeta o esforço e o desempenho novamente. Os autores concluem que a relação é circular e contínua: desempenho $\rightarrow$ satisfação $\rightarrow$ desempenho.

Ainda segundo Davis e Newstrom (1992), um funcionário satisfeito pode apresentar alta, média ou baixa produtividade, e o padrão de desempenho tende a permanecer. Os autores exemplificam com o caso dos atletas profissionais em que sucessos anteriores costumam deixá-los satisfeitos e com excesso de confiança, podendo assim acarretar derrotas. Neste caso, o papel do treinador seria mantê-los insatisfeitos renovando o desejo de vencer e jogar ainda melhor. Neste exemplo a insatisfação tenderia a produzir melhor desempenho.

Na mesma linha, o trabalho seminal de Vroom (1964) conclui que a relação entre satisfação no trabalho e desempenho não é simples. A depender das condições pode haver alta satisfação e baixo desempenho, baixa satisfação e alto desempenho, alta satisfação e alto desempenho ou até baixa satisfação e baixo desempenho, não sendo possível determinar se a satisfação é a causa de melhor desempenho ou se um melhor desempenho é a causa da satisfação. 
Associando a satisfação dos funcionários a dos clientes, Robbins (2005) argumenta que indivíduos satisfeitos tendem a falar bem da organização, a ajudar os colegas e realizar ações para além de suas atribuições regulares, influenciando positivamente na satisfação dos clientes.

A explicação dada pelo autor é que os clientes são sensíveis ao tratamento que recebem do pessoal da linha de frente. Como funcionários satisfeitos costumam atender melhor, com mais cortesia e dedicação e também tendem a permanecer na empresa por mais tempo, aumenta-se a probabilidade de os clientes serem atendidos por pessoas que já conhecem e que lhes atendem de modo satisfatório. Logo, a satisfação dos funcionários elevaria a satisfação e a lealdade dos clientes (ROBBINS, 2005).

Corroborando, Chiavenato e Matos (2009) afirmam que para satisfazer os clientes, é necessário primeiro satisfazer as pessoas que cuidam deles. Assim, para se atingir os objetivos estratégicos da organização é imprescindível que os trabalhadores estejam motivados e satisfeitos.

Por outro lado, para Parker (2007 apud WALGER; VIAPIANA e BARBOZA, 2014,) a insatisfação no trabalho promove comportamentos ruins como atrasos, ausências e demissão ou até atos contraproducentes como agressão, roubo e sabotagem. Nessa linha, Davis e Newstrom (1992) já argumentavam que funcionários insatisfeitos têm taxas mais altas de rotatividade, atrasos e faltas que funcionários satisfeitos, e alguns ainda roubam insumos da empresa, justificando-se como vingança pelos maus tratamentos, condições de trabalho e salário injusto.

Na mesma direção, Robbins (2005) concorda que funcionários insatisfeitos podem reagir de modo negativo, como pedindo demissão, aumentando as faltas ao trabalho ou reduzindo o empenho. Entretanto, observa que o comportamento pode ser positivo como propor melhorias à direção da empresa, ou mesmo esperar passivamente com otimismo por melhoras na organização.

A seção a seguir aborda o trabalho no ambiente bancário, discutindo aspectos que podem influenciar na satisfação dos indivíduos.

\section{Trabalho no Ambiente Bancário}

A carreira bancária é vista como altamente positiva pelos trabalhadores, que consideram que recebem salários e benefícios acima da média do mercado, têm expectativa de boa aposentadoria e podem crescer profissionalmente dentro das instituições (BRUNO, 2011). Consolidando essa perspectiva, sabe-se que além do salário, o bancário recebe por força de convenção coletiva de trabalho participação nos lucros ou resultados; auxílio refeição/alimentação; auxílio creche/babá; auxílio filhos com deficiência; auxílio funeral; vale-Cultura (FENABAN et al, 2015a, 2015b). Há casos ainda de bancos que oferecem plano de saúde, plano de previdência complementar. 
Por outro lado, no ambiente de trabalho, revela-se que o bancário enfrenta um cotidiano de pressões e intimidações, as metas de produtividade são cada vez mais inalcançáveis, a jornada diária é longa e cansativa, acumula-se tarefas e a rotina é repetitiva e mecanizada. Essas condições comprometem a integridade física e mental do trabalhador, sendo as LER/Dort primeira causa de adoecimento na categoria, seguida dos transtornos mentais como depressão, estresse ou ansiedade (BRUNO, 2011).

Note-se ainda que nos últimos anos, os bancos têm se concentrado na realização de negócios, diversificando e ampliando suas atividades para uma maior rentabilidade, que inclui a pressão por venda de produtos como cartões de crédito, seguros, previdência privada e títulos de capitalização pelos bancários (GRAVINA; ROCHA, 2006).

Com essa nova realidade, exige-se cada vez mais que o bancário seja mais qualificado, dominando conhecimentos que inclui desde mercado financeiro até domínio das novas tecnologias. Além disso, a responsabilidade pela qualificação passa a ser do próprio trabalhador, que corre o risco de não conseguir promoção e até perder o emprego se não estiver qualificado (MERLO; BARBARINI, 2002).

Nesse contexto antagônico de trabalho insalubre e gratificante, diversas pesquisas têm sido realizadas sobre a temática satisfação do trabalho no ambiente bancário no Brasil. Santos (2011), com sua pesquisa no Banco do Brasil, identificou que em geral os trabalhadores das agências pesquisadas estão satisfeitos com o trabalho, sendo a dimensão com maior índice de satisfação a dimensão "satisfação com a chefia". Jacob (2012) pesquisou em uma agência de Ouro Preto e identificou que a dimensão "satisfação com os colegas de trabalho" foi a que apresentou o maior índice de satisfação e a dimensão "satisfação com o salário" foi a que apresentou o menor índice de satisfação. No estudo realizado por Nogueira; Lopes; Rocha e Silva; Farias (2013), identificou-se insatisfação quanto ao número de funcionários lotados na agência e o volume de trabalho, que tende a ser desigual.

A seguir serão apresentados os aspectos metodológicos que orientaram a presente investigação, tais como tipo de pesquisa e métodos e instrumentos de coleta de dados.

\section{Metodologia}

Esta pesquisa é de natureza aplicada, pois tem como motivação analisar um problema concreto e prático. Pode-se ainda classificar a presente pesquisa como exploratória, vez que se propôs analisar um problema nos limites de uma realidade específica (GIL, 2008).

Quanto aos procedimentos é bibliográfica, uma vez que foi feita a revisão do referencial bibliográfico disponível, para aprofundamento do tema e subsidiar a análise dos dados (GIL, 2008). 
Nesta pesquisa os referenciais utilizados foram livros da biblioteca da Caixa Econômica Federal (CEF), monografias disponibilizadas na internet da UNB e USP, artigos disponibilizados na internet por diversas revistas cientificas pesquisados por meio do site "Google Acadêmico".

A presente também se caracteriza como estudo de caso, "uma categoria de pesquisa cujo objeto é uma unidade que se analisa aprofundadamente" (TRIVINOS, 1987, p. 133). Quanto à abordagem do problema é qualitativa e quantitativa, vez que aplicamos questionário quantitativo e realizamos entrevistas qualitativas.

O grupo de participantes do estudo foi composto dos empregados efetivos da CEF lotados na agência Cícero Dantas, na cidade de Cícero Dantas - BA, selecionados por conveniência.

Em uma fase exploratória desta investigação, com vistas a aproximação do lócus de pesquisa e apropriação da temática, foram coletados dados por meio da Escala de Satisfação no Trabalho em sua versão completa. Acrescentou-se à escala 08 questões relacionadas aos dados demográficos e funcionais de interesse da pesquisa.

A Escala de Satisfação no Trabalho (EST), foi construída e validada no Brasil para medir o nível de satisfação dos empregados. Aborda cinco dimensões: satisfação com o salário, satisfação com os colegas de trabalho, satisfação com a chefia, satisfação com as promoções e satisfação com a natureza do trabalho (SIQUEIRA, 2008).

A EST é composta de 25 itens (em sua versão completa), aos quais os trabalhadores respondem por meio de uma escala de 1 a 7 pontos. Os resultados são apurados como escores médios de cada uma das cinco dimensões. Na interpretação dos resultados considera-se quanto maior o valor do escore médio maior o grau de satisfação do empregado com a dimensão. Assim, valores entre 5 e 7 indicam satisfação. Por outro lado, valores entre 1 e 3,9 indicam insatisfação, enquanto valores entre 4 e 4,9 informam um estado de indiferença (SIQUEIRA, 2008).

As qualidades psicométricas da EST podem ser atestadas pelas altas cargas fatoriais de seus 25 itens cujos valores ficaram entre 0,49 a 0,88. A escala também obteve índices satisfatórios de precisão para cada uma das cinco dimensões, os altos valores de precisão (alfa de Cronbach) variam de 0,82 a 0,92 (SIQUEIRA, 2008).

Para realização das entrevistas e aplicação do questionário EST foi explanado ao gerente geral da agência do que se trata a presente pesquisa, seus objetivos e importância, e o mesmo concedeu autorização para aplicação do questionário. A abordagem aos participantes foi mediante comunicação oral individualmente, em que foram explanados os objetivos e importância da presente pesquisa.

O questionário foi aplicado no mês de fevereiro de 2016 no próprio ambiente de trabalho. Todos os 06 participantes responderam o questionário, deste modo não houve problema na abordagem ou na aplicação do questionário. Os dados foram analisados quantitativamente usando estatística descritiva com a auxílio do software Microsoft Office Excel 2007 para tabulação dos dados e construção das tabelas. 
Para a coleta dos dados qualitativos, foram realizadas entrevistas semi-estruturadas com o mesmo grupo de respondentes, no mês de março, no próprio ambiente de trabalho. Entrevista semiestruturada é aquela em que o entrevistador "se utiliza de questões previamente definidas, porém tem a liberdade de ampliar as questões no decorrer da entrevista" (TRIVINOS, 1987, p. 146).

Para tanto, utilizou-se um roteiro semi-estruturado contendo 13 questões, sendo três de natureza geral (principais causas de satisfação e insatisfação no trabalho e sugestões para melhoria do nível de satisfação dos funcionários), e duas correspondentes a cada dimensão da escala de satisfação no trabalho. Para o registro das informações foi utilizado equipamento digital de gravação, mediante a autorização dos entrevistados.

Para análise dos dados coletados nas entrevistas, adotou-se a análise de conteúdo, sendo que as dimensões da escala EST foram tomadas como categorias de análise. Trivinos (1987, p. 160) esclarece que a análise de conteúdo consiste em um conjunto de técnicas utilizadas para estudar as comunicações humanas com foco no conteúdo das mensagens.

A seguir, serão apresentados os resultados obtidos com a aplicação do questionário EST e realização das entrevistas.

\section{Apresentação e Análise dos Resultados}

A partir da tabulação dos dados gerados através da aplicação dos questionários da pesquisa quantitativa, e da análise dos dados da entrevista qualitativa, foram obtidos resultados que serão apresentados nesta etapa.

Dentre os participantes, todos são do sexo masculino. A maioria (50\%) tem idade entre 31 a 40 anos, 33,33\% tem idade abaixo de 31 anos e 16,67\% acima de 40 anos. Quanto ao estado civil a maioria $(66,67 \%)$ é casado/união estável, $33,33 \%$ é solteiro. A maioria $(66,67 \%)$ não possui filhos, $16,67 \%$ possui um filho e $16,67 \%$ possui dois filhos. Quanto a escolaridade a maioria (50\%) possui pós-graduação completa ou incompleta, $16,67 \%$ graduação completa e 33,33\% graduação incompleta. Quanto ao tempo de serviço na empresa a maioria (50\%) tem entre 2 e 4 anos, 33,33\% tem entre 5 e 10 anos e 16,67\% tem mais de 10 anos de admissão na empresa. A maioria (50\%) exerce a função de gerente, $33,33 \%$ exerce a função de caixa e apenas 16,67\% não possui função.

Quanto à dimensão satisfação com os colegas, os dados mostram que os entrevistados em unanimidade nutrem elevada satisfação com os colegas de trabalho. Para eles os relacionamentos vão alem da cordialidade profissional, tornando-se amigos. Os conflitos, quando surgem, são resolvidos rapidamente por meio do dialogo prevalecendo o bom clima de trabalho. Reproduzem-se abaixo algumas falas que destacam essa relação: 
Geralmente meus melhores amigos são ex-colegas de trabalho e atuais colegas de trabalho. (Entrevistado 3)

É mais que colegas de trabalho, você percebe aquela coisa de um ajudar o outro, mesmo que às vezes não ta na sua função. (Entrevistado 1)

Um ou outro deslize pontual de atitude ou comportamento anti-coletivo é suprimido pelo clima de amizade e respeito mútuos. (Entrevistado 2)

Sendo assim, pode-se afirmar que na unidade pesquisada a colaboração, a amizade, a confiança e o relacionamento mantidos com os colegas de trabalho propiciam aos empregados sentimentos gratificantes ou prazerosos. Nesse sentido, recorde-se que Chiavenato (2015) chama atenção que o convívio social e as experiências compartilhadas com os colegas de trabalho são fontes de satisfação no trabalho.

Também quando da aplicação da EST, o escore médio atingido foi de 6,23, sinalizando que os funcionários estão satisfeitos nessa dimensão "satisfação com os colegas". Esta foi a dimensão que obteve o maior escore médio. A pesquisa mostrou ainda que os funcionários estão satisfeitos com todos os itens desta dimensão.

No que se refere à satisfação com o salário, as entrevistas mostram que não houve consenso vez que demonstraram sentir-se satisfeitos e compartilharam do sentimento de satisfação com a participação nos lucros (PLR), mas quando comparado o salário com o trabalho desempenhado alguns declararam estar insatisfeitos. Os trechos a seguir ilustram essa percepção:

Me sinto feliz [quando recebe o salário], mas eu sei que também sou merecedor pelo esforço empreendido aqui no trabalho, porque o trabalho aqui é realmente muito desgastante, mas acredito que sou bem recompensado por isso. (Entrevistado 5)

[...] Não me sinto muito legal não com o salário. A PLR até que é boa, valor razoável, me sinto satisfeito em participar dos lucros. O salário tem que melhorar um pouco. (Entrevistado 1).

Trabalhamos bastante com trabalho dificil, com uma grande responsabilidade $e$ acho que deveríamos ser todos melhor remunerados. (Entrevistado 3)

Acredito ser [o salário] suficiente pelas atividades desempenhadas. (Entrevistado 4)

Conforme visto no referencial, um dos fatores que levam a altos índices de satisfação é o salário justo levando em consideração as atribuições do cargo, o custo de vida e a média salarial do mercado (ROBBINS, 2005). Como os entrevistados não foram consensuais quanto à satisfação com o salário, tende a haver a percepção de salários injustos para algumas funções.

Esta dimensão obteve escore médio 4,73 sinalizando estado de indiferença. No quadro 3 , observa-se que na EST os itens com menor índice nessa dimensão são comparativos do salário com o quanto se trabalha e com os esforços despendidos no trabalho, isso nos mostra que o bancário enfrenta 
tanta sobrecarga no trabalho que sente que o dinheiro recebido não é suficiente para compensar todos os esforços.

Quadro 3- Escore médio por questão da dimensão satisfação com o salário.

\begin{tabular}{l|rr}
\hline \multicolumn{1}{c||}{ Item } & Média & $\begin{array}{l}\text { Desvio } \\
\text { Padrão }\end{array}$ \\
\hline \hline 5 Com o meu salário comparado com o quanto eu trabalho. & 4,33 & 1,75 \\
8 Com o meu salário comparado à minha capacidade profissional. & 5,17 & 1,33 \\
12 Com o meu salário comparado ao custo de vida. & 4,83 & 1,17 \\
15 Com a quantia em dinheiro que eu recebo desta empresa ao final de cada mês. & 5,00 & 1,10 \\
21 Com meu salário comparado aos meus esforços no trabalho. & 4,33 & 1,51 \\
\hline Escore Médio Dimensão Satisfação com o salário & $\mathbf{4 , 7 3}$ & \\
\hline
\end{tabular}

Fonte: Elaborado pelo autor.

Em se tratando de satisfação com a chefia, os entrevistados foram consensuais em afirmar que há espaço para expor ideias ou sugestões ao seu chefe. Quanto ao estilo de gerenciamento avaliaram de forma positiva, sendo as definições: estilo político de bom relacionamento, participativo, estilo liberal, estilo muito tranquilo e bom estilo de gerenciamento. A seguir algumas falas sobre esta dimensão:

O meu chefe imediato é aquele estilo político de bom relacionamento, tanto com os clientes quanto os funcionários subordinados. (Entrevistado 1).

Participativo. Acho positivo o comportamento reflexivo de um colega considerado inteligente por muitos e que já passou por diversas áreas da CAIXA. Tem demonstrado preocupar-se com o lado pessoal da equipe sob sua gestão. (Entrevistado 2)

Estilo muito tranqüilo, ele tem um bom dialogo, sabe lidar com a equipe e presta um importante papel como gerente da agência. (Entrevistado 5)

O meu chefe eu acho que acata minhas ideias sim, na medida do possível. (Entrevistado 3).

As falas acima demonstram contentamento com a organização e capacidade profissional do chefe, com o seu interesse pelo trabalho dos subordinados e entendimento entre eles. Segundo Chiavenato (2015) um ambiente com comunicação aberta (transparente, sem ruídos e barreiras) é fonte de satisfação no trabalho, sendo que um dos itens que levam a altos índices de satisfação é o chefe compreensivo (ROBBINS, 2005).

Da mesma forma, o escore médio atingido de 5,40 corrobora que os funcionários estão satisfeitos. No quadro 4 abaixo temos os escores médios por questão da dimensão satisfação com a chefia. 
Quadro 4 - Escore médio por questão da dimensão satisfação com a chefia.

\begin{tabular}{l|rr}
\multicolumn{1}{c|}{ Item } & Média & $\begin{array}{l}\text { Desvio } \\
\text { Padrão }\end{array}$ \\
\hline \hline 2 Com o modo como meu chefe organiza o trabalho do meu setor. & 5,17 & 0,98 \\
9 Com o interesse de meu chefe pelo meu trabalho. & 5,33 & 1,03 \\
19 Com o entendimento entre eu e meu chefe. & 5,33 & 0,82 \\
22 Com a maneira como meu chefe me trata. & 5,50 & 1,05 \\
25 Com a capacidade profissional do meu chefe. & 5,67 & 0,82 \\
\hline Escore Médio Dimensão Satisfação com a chefia & $\mathbf{5 , 4 0}$ & \\
\hline
\end{tabular}

Fonte: Elaborado pelo autor.

Quando abordados sobre a natureza do trabalho, os participantes foram críticos quanto às condições de trabalho, em especial apontando que a quantidade de funcionários é insuficiente para atender elevada demanda de clientes gerando sobrecarga de trabalho aos poucos funcionários, como se observa nos trechos a seguir:

Está péssima [a condição de trabalho]. Volume de trabalho versus mão de obra está incompativel. Principalmente porque tiraram um funcionário aqui da agência, que já era sobrecarregado com o quantitativo que tinha e com um a menos esta muito mais sobrecarregado [...]. A demanda é muito grande. (Entrevistado 1)

Ruins [as condições de trabalho]. A CAIXA entrou num processo de expansão motivada pela necessidade de ampliação de estrutura, mas o observado foi exatamente o oposto: Novas unidades que serviriam para desafogar agências mais antigas criaram uma nova demanda vinda dos mercados onde passou a atuar com agências recém-instaladas. [...] (Entrevistado 2).

Quanto ao trabalho realizado, grande parte dos entrevistados demonstraram sentimento de ambiguidade por estarem satisfeitos e realizados, mas reconhecem que as condições de trabalho interferem nessa dimensão. Os trechos a seguir ilustram esse achado:

Realizado por um lado e desmotivado por outro, dadas as condições [de trabalho]. (Entrevistado 2)

Por um lado eu me sinto feliz com o que eu faço, eu gosto muito do que eu faço, por outro lado eu vejo que a estrutura aqui da agência é um pouco deficitária em relação à quantidade de funcionários para atender ao público. (Entrevistado 5)

Agora perante a sociedade não me sinto valorizado por ser bancário, a sociedade tem estereótipo de que bancário é enrolado, ladrão, preguiçoso, então não é orgulho ser bancário, eu não sinto orgulho de ser bancário. (Entrevistado 1)

No trabalho aqui, eu me esforço bastante, me identifico com algumas coisas outras não, mas, enfim, me sinto satisfeito pelo trabalho desempenhado. [...] Bancário, principalmente em uma cidade pequena como é o caso de Cícero Dantas, você ganha um prestígio bem maior do que você tinha anteriormente. [...] O trabalho em si me causa satisfação, que eu acho o trabalho interessante [...] (Entrevistado 3) 
Cabe ressaltar que esse resultado pode ser reflexo das condições de trabalho a que são submetidos os bancários, quais sejam, cobrança constante para o alcance de metas inalcançáveis, sobrecarga de trabalho, atividades que exigem do trabalhador elevada responsabilidade, quadro de funcionários reduzido e insuficiente para o atendimento das demandas. As condições de trabalho citadas pelos entrevistados se assemelham às descritas por: Maximo; Araujo; Zambroni-de-Souza (2014), Bruno (2011), Gravina; Rocha (2006), Nogueira; Lopes; Rocha e Silva; Farias (2013).

Percebe-se ainda que o descontentamento dos participantes não é com a natureza das atividades, mas sim com as condições de trabalho e com a fixação de metas, que não levam em consideração a realidade econômica atual do país e da região demográfica em que está inserida a agência, como se observa nos trechos a seguir:

A forma que são cobradas as metas sem analisar o dia-a-dia de cada unidade. (Entrevistado 4)

Também fico insatisfeito com a cobrança de metas de produção que acaba tendo, nesse meio, você tem tudo contra, não tem estrutura, não tem um apoio e ainda tem a cobrança que é absurdo isso. (Entrevistado 1)

Destaque-se ainda o posicionamento de um entrevistado de que o reconhecimento por parte dos clientes traz elevada satisfação, porém a insatisfação e as reclamações dos clientes trazem elevada insatisfação para os funcionários. O trabalho de Robbins (2005) já nos mostra que a satisfação dos clientes afeta a satisfação dos funcionários e manter contato regular com clientes que se comportam de maneira rude, insensível ou irracional afeta negativamente a satisfação no trabalho. Abaixo reproduzem-se os comentários do entrevistado:

É reconhecimento, [o que traz satisfação no trabalho], principalmente do cliente, dos colegas é bom, mas principalmente quando vem dos clientes, quando você resolve algum problema, ou faz algum empréstimo, financiamento de casa, a primeira casa da pessoa, você vê o cliente satisfeito é legal. E também o contraposto, a maioria dos clientes insatisfeitos é a pior coisa que tem, estressa demais.

Os clientes [é o que traz insatisfação no trabalho], por que a maioria dos clientes não entende que o problema é estrutural, é da empresa, e acabam descontando no funcionário. Então a questão da demora no atendimento, falta de estrutura, falta de tecnologia, que o empregado não tem como interferir acaba sendo responsabilizado por aquilo. Esses fatores causam a insatisfação dos clientes e por conseqüência acaba sendo jogado em cima do empregado. (Entrevistado 1) 
Esse comentário esta alinhado com a pesquisa realizada com gerentes de banco por Maximo, Araujo e Zambroni-de-Souza (2014), cuja principal fonte de prazer no trabalho apontada pelos participantes foi o atendimento aos clientes.

Quanto à EST, esta foi a dimensão que obteve o menor escore médio $(4,43)$. O item satisfação com as preocupações exigidas pelo meu trabalho obteve escore 3,00 indicando elevado grau de insatisfação dos participantes.

No que se refere à satisfação com as promoções, os dados coletados na entrevista mostram opiniões antagônicas. Alguns entrevistados consideraram como positiva a forma como são realizadas as promoções, de forma transparente e justa, enquanto outros consideraram que na prática nem sempre as promoções ocorrem de modo transparente e justo, ocasionando eventualmente insatisfação em alguns funcionários:

A empresa presa por transparência e justiça no processo de promoção, apesar de por vezes mal interpretado. [...] a construção de equipes com pessoas que na ótica do gestor são confiáveis para determinado trabalho nem sempre é vista com bons olhos entre os que pleiteiam uma promoção. (Entrevista 2)

O banco que trabalho possui um sistema de promoção muito favorável para quem busca um crescimento e conhecimento de forma rápida. [...] A avaliação do banco para promoção é satisfatória, ela vai variando de acordo com alguns cargos, $e$ avalia comportamento, conhecimento, habilidades e atitudes. O famoso "CHA". (Entrevistado 6)

Infelizmente são baixas [as oportunidades de promoção], e eu achava que não existia no serviço público, mas existe muito a questão do quem indica. Então às vezes falta de critérios objetivos, na teoria tem os critérios objetivos, mas muitas vezes a gente percebe não são cumpridos, pessoas passando na frente por uma tangente do "QI" acontece muito. (Entrevistado 1)

Eu critico a parte política que tem, tem vez que nem só política de agentes políticos, mas também de próprios colegas, "ah por amizade eu trago fulano", isso merece ser criticado. Mas quando é aplicado o Programa de Seleção Interna, seguindo o normativo, é muito bem feito. (Entrevistado 3)

Corroborando os dados da entrevista, esta dimensão obteve escore médio 4,67 na EST sinalizando estado de indiferença. A tendência é de contentamento maior daqueles que estão nos níveis hierárquicos maiores e descontentamento daqueles que estão nos menores níveis hierárquicos. No quadro 5 abaixo temos os escores médios por questão da dimensão satisfação com as promoções. 
Id on Line Revista Multidisciplinar e de Psicologia

Id on Line Multidisciplinary and Psychology Journal

Quadro 5 - Escore médio por questão da dimensão satisfação com as promoções.

\begin{tabular}{ll|rr}
\multicolumn{1}{c|}{ Item } & Média & $\begin{array}{c}\text { Desvio } \\
\text { Padrão }\end{array}$ \\
\hline \hline 3 Com o número de vezes que já fui promovido nesta empresa. & 5,17 & 2,14 \\
4 Com as garantias que a empresa oferece a quem é promovido. & 4,67 & 1,37 \\
10 Com a maneira como esta empresa realiza promoções de seu pessoal. & 4,50 & 1,22 \\
16 Com as oportunidades de ser promovido nesta empresa. & 4,33 & 1,97 \\
20 & & \\
$\quad$ Com o tempo que eu tenho de esperar para receber uma promoção nesta & 4,67 & 1,51 \\
\hline Escore Médio Dimensão Satisfação com as promoções & $\mathbf{4 , 6 7}$ & \\
\hline
\end{tabular}

Fonte: Elaborado pelo autor.

A seguir apresenta-se a síntese dos principais achados nesse trabalho, suas limitações e sugestões para novas pesquisas.

\section{Considerações Finais}

O presente artigo analisou o nível de satisfação no trabalho dos empregados de uma agência da Caixa Econômica Federal no Estado da Bahia. Em resposta ao objetivo proposto, pode-se afirmar que, com base nas entrevistas realizadas e dados do questionário EST, os funcionários indicam um estado de contentamento quanto à satisfação geral no trabalho.

Ainda nesse sentido, sobre os objetivos específicos propostos, pode-se afirmar que os entrevistados foram unânimes em demonstrar elevada satisfação com os colegas de trabalho, destacando-se que os relacionamentos ultrapassam as relações de trabalho, formando sólidas amizades. Por outro lado, nas entrevistas os participantes revelaram críticas quanto às condições de trabalho e quantidade de funcionários insuficiente para atender elevada demanda de clientes, gerando sobrecarga de trabalho aos poucos funcionários.

Os dados da entrevista estão alinhados aos resultados apresentados pelo questionário EST, onde a dimensão que obteve o maior índice foi "Satisfação com os colegas", com escore 6,2 sinalizando que os empregados estão muito satisfeitos nessa dimensão. A dimensão que obteve o menor índice $(4,43)$ foi "Satisfação com a natureza do trabalho", sinalizando estado de indiferença quanto a esta dimensão.

Os dados aqui apresentados podem ser úteis à organização estudada para formulação e reformulação de políticas organizacionais com vistas a sanar as insatisfações apresentadas pelos participantes e manter os itens satisfatórios, com vistas a aumentar a satisfação no trabalho na unidade. Como também, as análises apresentadas nesta investigação podem elucidar aspectos apontados em 
outras pesquisas já realizadas, contribuindo para uma melhor compreensão do tema no meio acadêmico.

No que tange a investigações futuras, vislumbra-se a possibilidade de fazer um comparativo entre os resultados produzidos com empregados de bancos públicos e aqueles de bancos privados, a fim de melhor evidenciar se há diferenças na satisfação no trabalho entre os dois grupos, de tal modo que se sugere a realização de investigação semelhante em outras agências, com número maior de empregados

Reconhece-se que esta pesquisa apresenta a limitação de ter sido realizada em apenas uma agência bancária e com pequeno número de participantes, não sendo possível, portanto, generalizar os resultados quantitativamente para outras agências ou para todos os funcionários da CEF. De outra perspectiva, ao se optar também pela abordagem qualitativa, foi possível conhecer em profundidade uma realidade delimitada e os resultados podem permitir formular hipóteses para o encaminhamento de outras pesquisas (TRIVINOS, 1987, p. 111).

Por fim, reconhecendo-se a temática satisfação no trabalho é de interesse não somente da Caixa Econômica Federal e de seus funcionários, espera-se que o presente trabalho tenha contribuído como reflexões frutíferas também para os pesquisadores da área, estimulando a continuidade do estudo desse tema no ambiente bancário.

\section{Referências:}

AZIRI, B. Job Satisfaction: a Literature Review. Management Research and Practice. Tetovo, v. 3, n. 4, p. 77-86, dez. 2011.

BRUNO, W. P. Bancários não são máquinas. In: SZNELWAR, Laerte Idal. Saúde dos bancários. São Paulo: Publisher Brasil: Editora Gráfica Atitude Ltda, 2011. p. 21-31.

CAIXA. Quem faz a CAIXA. 2014. Disponível em: $<$ http://www1.caixa.gov.br/relatorio_sustentabilidade_2013/quem-faz.html $>$. Acesso em: 13 dez. 2015.

CHIAVENATO, I. Gerenciando com as pessoas: transformando o executivo em um excelente gestor de pessoas. Barueri: Manole, 2015.

CHIAVENATO, I.; MATOS, F. G. Visão e ação estratégica: os caminhos da competitividade. 3. ed. Barueri: Manole, 2009.

DAVIS, K.; NEWSTROM, J. W. Comportamento humano no trabalho: uma abordagem psicológica. Tradução Cecília W. Bergamini e Roberto Coda. São Paulo: Pioneira, 1992.

FENABAN et al. Convenção coletiva de trabalho [dos bancários] 2015/2016. São Paulo, 2015. Disponível em: 〈http://www.spbancarios.com.br/Uploads/PDFS/1007_CCT_2015_2016.pdf〉. Acesso em: 21 fev. 2016. 
FENABAN et al. Convenção coletiva de trabalho sobre participação dos empregados nos lucros ou resultados dos bancos em 2015. São Paulo, 2015. Disponível em: <http://www.spbancarios.com.br/Uploads/PDFS/1006 CCT_plr 2015 2016.pdf $>$. Acesso em: 21 fev. 2016.

GRAVINA, M. E. R.; ROCHA, L. E. Lesões por Esforços Repetitivos em bancários: reflexões sobre o retorno ao trabalho. Cad. psicol. soc. trab., São Paulo, v. 9, n. 2, p. 41-55, dez. 2006. Disponível em: $<$ http://pepsic.bvsalud.org/scielo.php?script=sci arttext\&pid=S1516-

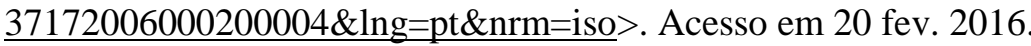

GIL, A. C. Métodos e técnicas de pesquisa social. 6. ed. São Paulo: Atlas, 2008.

JACOB, S. A. A satisfação dos funcionários de uma agência bancária em Ouro Preto do Oeste em relação aos indicadores de qualidade de vida no trabalho. 2012. $47 \mathrm{f}$. Monografia (bacharelado) - Universidade de Brasília, Ji-Paraná, 2012. Disponível em: <http://bdm.unb.br/handle/10483/3932>. Acesso em: 14 fev. 2016.

MARX, K. O capital: crítica da economia política. Tradução de Regis Barbosa e Flávio R. Kothe. São Paulo: Nova Cultural, 1996.

MAXIMO, T. A. C. O.; ARAUJO, A. J. S.; ZAMBRONI-DE-SOUZA, P. C. Vivências de sofrimento e prazer no trabalho de gerentes de banco. Psicol. cienc. prof., Brasília, v. 34, n. 1, p. 96-111, mar. 2014. Disponível em: $\quad \underline{\mathrm{http}} / / / \mathrm{www} \cdot$ scielo.br/scielo.php?script=sci arttext\&pid=S1414-

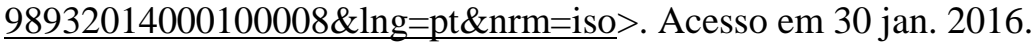

MERLO, Á. R. C.; BARBARINI, N. Reestruturação produtiva no setor bancário brasileiro e sofrimento dos caixas executivos: um estudo de caso. Psicologia \& sociedade. Vol. 14, n. 1 (jan./jun. 2002), p. 103-122, 2002.

NOGUEIRA, G. J. M. R. et al. A percepção dos colabores de uma agência bancária sobre o seu trabalho. In: Simpósio de Excelência em Gestão e Tecnologia, 10., 2013, Resende. Anais... Resende: AEDB, 2013. Disponível em: <http://www.aedb.br/seget/arquivos/artigos13/19118318.pdf>. Acesso em: 16 fev. 2016.

ROBBINS, S. P. Comportamento Organizacional. 11. ed. São Paulo: Pearson Prentice Hall, 2005.

SANTOS, C. R. Satisfação no Trabalho: comparação da satisfação no trabalho dos funcionários lotados em agências bancárias abertas e agências fechadas. 2011. 33 f. Monografia (bacharelado) Universidade de Brasília, Brasília, 2011. Disponível em: 〈http://bdm.unb.br/handle/10483/2525>. Acesso em: 14 fev. 2016.

SIQUEIRA, M.M.M. Medidas do comportamento organizacional: Ferramentas de diagnóstico e de gestão. Porto Alegre: Artmed, 2008.

TRIVINOS, A. N. S. Introdução à pesquisa em ciências sociais: a pesquisa qualitativa em educação. São Paulo : Atlas, 1987.

VROOM, V. H. Work and motivation. Nova York: John Wiley \& Sons, 1964.

WALGER, C.; VIAPIANA, L.; BARBOZA, M. M. Motivação e satisfação no trabalho: em busca do bem-estar de indivíduos e organizações. Curitiba: InterSaberes, 2014. 
Id on Line Revista Multidisciplinar e de Psicologia

Id on Line Multidisciplinary and Psychology Journal

WEISS, H. M. 2002. Deconstructing job satisfaction: separating evaluations, beliefs and affective experiences. Human resource management review. West Lafayette, v. 12, n. 2, p. 173-194, 2002.

XAVIER, E. P. Comportamento organizacional: psicologia aplicada à administração. Porto Alegre: Bureau, 1973.

Como citar este artigo (Formato ABNT):

PAIXÃO, A.R.; BARBOSA. M.A.C. Satisfação no Trabalho: Um estudo na Agência da caixa Econômica Federal de Cícero Dantas - BA. Id on Line Revista Multidisciplinar e de Psicologia, Julho de 2016, vol.10, n.30. supl. 1. p. 10-26. ISSN 1981-1179.

Recebido: 10/04/2016

Aceito: 16/04/2016 